\title{
Mechanical Behaviour of Orthopaedic Cement Loaded with Antibiotics in the Operation Room
}

\author{
RADU FLEACA ${ }^{1}$, SEBASTIAN IOAN CERNUSCA MITARIU ${ }^{1}$, VALENTIN OLEKSIK ${ }^{2 *}$, MIHAELA OLEKSIK ${ }^{2}$, MIHAI ROMAN ${ }^{1}$ \\ ${ }^{1}$ Lucian Blaga University of Sibiu, Faculty of Medicine, 2A Lucian Blaga Str., 550169, Sibiu, Romania \\ ${ }^{2}$ Lucian Blaga University of Sibiu, Faculty of Engineering, 4 Emil Cioran Str., 550025, Sibiu, Romania
}

\begin{abstract}
Using antibiotic impregnated cementis an important mean to treatand prevent periprostetic joint infections. This complication requires for treatment important financial and technical resources. Adding antibiotics to orthopaedic cement may alter its mechanical properties with possible reduced time of prosthesis survival rate. This study analyze the mechanical properties of cement mixed with antibiotics in the operation room, which helps reducing costs and permit a more specific antibiotic local therapy. All tested antibiotics used in this study does not change the mechanical behavior of the orthopaedic cement when mixed in therapeutic doses, all alterations seems to be at a level below clinical significance. Mixing antibiotics in Orthopedic cement leads to minor decrease of the mechanical properties for cefazolin, cefuroxime, ceftazidime, meropenem and vancomycin and a mechanical significant decrease for gentamicin and clindamycin.
\end{abstract}

Keywords: orthopaedic cement, polymethylmethacrylate, antibiotic, mechanical properties, periprostetic joint infection

With increasing number of total joint replacements performed worldwide, there are also an increased number of periprostetic jointinfections, despite all measures taken against this important complication. Failures cause new complications for patients, lengthen the healing process and increase cost. [1] One of the means an orthopaedic surgeon has against these infections is the use of antibiotic loaded cement (polymethylmethacrylate) (PMMA) obtained by polymerizing the methyl methacrylate monomer (MMA). This can be used as prophylaxis [2, 3], for the aseptic joint replacement or as treatment during different stages of septic revisions [4]. Mixing antibiotics in orthopaedic cement allows local delivery on antibiotics at the implant site immediately after surgery [5]. There are only few antibiotics preloaded in the orthopaedic cement by the producing companies and with a significant increased cost for each cement dose, available in Europe since 1970 and in United States from 2003 [6].

Modern treatment requires specific antibiotherapy, so the need for various antibiotics loaded in the cementfor an accurate treatment. The solution is to mix different antibiotics in the cement. An antibiotic to be mixed with the cement must be thermally stable with the exothermic reaction of polymerization, must not compromise the mechanical integrity of the cement and must elute from the cement for a certain period of time [7]. There are few studies regarding the mechanical properties of these cements mixed in the operating theatre $[8,9]$, the majority of studies are targeted on the dose and time of local released antibiotic [10-13].

Our study analyzes the mechanical properties of orthopaedic cement mixed with different antibiotics compared with the original nonloaded native cement, as a factor that may influence the survival rate of the prosthesis.

\section{Experimental part}

For this analysis we have used Palamed Cement produced by Heraeus. For each bar we have mixed two portions of cement $(2 \times 40 \mathrm{~g}$ ). Temperature for mixing the cement was 18 degrees Celsius, controlled in the operation room. For the creation of the experimental bars we have mixed the cement with the vacuum mixing device as for the real surgery. Postak in 2006 show that the vacuum mixed cement with Gentamicin specimens had the greatest fatigue life, the the hand-mixed was the weakest and strongly suggests that both hand-blending and open hand-mixing of antibiotics at the time of surgery should be avoided. This study and the necessity of having more homogenous cement determined us to use the vacuummixing device for the cement [14].

In the recipient of the vacuum mixing device we have introduced first the cement powder, then the antibiotic and then the polymerizing solvent. After mixing, the material was mould in a shape $63 \times 63 \mathrm{~mm}$ and pushed with a metal top for pressurizing the material inside the shape. After the polymerization each piece was measured. Using this technique we have realized 16 bars, two for each antibiotic selected and two without antibiotic as reference for the original orthopaedic cement. We have used antibiotics known for preserving their biologic properties after the polymerization of the cement and in doses recommended by the Cincinnati 2013 Consensus for treating periprostetic joint infections, as shown in table 1.

Each of the 16 experimental bars was randomized numbered from 1 to 16 . The bars were then blinded tested by the engineering team. The large $63 \times 63 \mathrm{~mm}$ bars were then cut with high pressurised water machine in $30 \mathrm{x} 30 \mathrm{x}$ $22 \mathrm{~mm}$ bars. We have chosen this type of bars because of their flat surfaces that can be measured easily using the main system Aramis strains.

One of the $30 \times 30 \mathrm{~mm}$ surface of each bar was then prepared for image acquisition with the Optic System Aramis Gom. For this, samples were prepared in such a way that there are flat parallel surfaces of each bar. Usually, the preparation of samples for optical analysis is done by applying a white paint on open area analyzed in order to increase contrast. Since cement both standard sample and mixed with different types of antibiotics had a light green color (fig. 1) it was not necessary to apply this coating of paint. This is beneficial because in many cases this layer influences the values of the major and minor strain. Thus, the area under review was sprayed just with a fine powder black of graphite. Aramis system cameras used was two cameras with a fixed focal length of $50 \mathrm{~mm}$. The cameras 
Table 1

TYPE AND DOSE OF ANTIBIOTIC MIXED WITH ORTHOPAEDIC CEMENT

\begin{tabular}{|l|l|l|}
\hline Antibiotic & International Common Name & Dose for 40 grams Cement \\
\hline Lyzolin & Cefazolin & 2 grams powder \\
\hline Cefuroxima & Cefuroxime & 1,5 grams powder \\
\hline Meropenem A & Meropenem & 1 gram powder \\
\hline Gentamicin Krka & Gentamicin & 240 milligrams solution \\
\hline Ceftamil & Ceftazidime & 2 grams powder \\
\hline Vancocin & Vancomycin & 1 gram powder \\
\hline Clindamycin & Clindamycin & 1200 milligrams solution \\
\hline
\end{tabular}

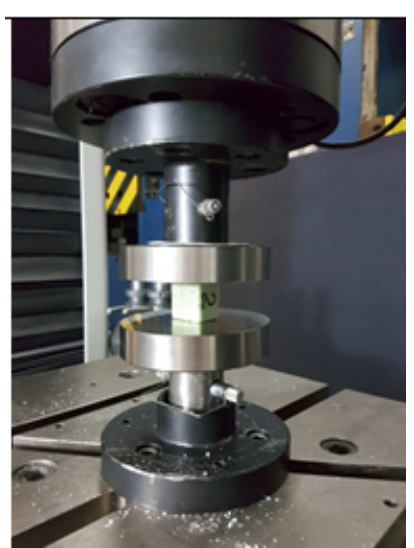

Fig. 1. Bar fixed in the Instron Machine at the beginning of a compression test

apertures were set at 5.6 to obtain a better image clarity and a better accuracy of the results, even if an opening of 2.8 it has been possible to set. The exposure time was 125 ms. Images were acquired during compression test until the moment of the first cracks appears.

We have used the rectangular bars with dimensions 30 $\times 30 \times 22.5 \mathrm{~mm}$ as described before. To conduct the tests we have used the Machine for testing compression and buckling Instron 5587, which has a maximum force of 300 $\mathrm{kN}$, as shown in figure 1.

\section{Results and discussions}

As standards requires, the compression testends when the first crack occurred. For this reason and in order to determine also the local strains in parallel with the compression test, using Aramis program, we have acquired images with an acquisition rate of 1 image / $\mathrm{s}$.

Maximum compression stress does not represent a value that can be taken into account because it depended on moment when the test machine senses the breaking point. For the same reason we cannot evaluate the deformation corresponding to the maximum compression. Therefore, in all cases, bone cement having elastic-plastic

\begin{tabular}{|l|c|c|c|}
\hline \multicolumn{1}{|c|}{ Test Bar } & The E modulus & The yield stress & The compression \\
& {$[\mathrm{MPa}]$} & {$[\mathrm{Mpa}]$} & $\begin{array}{c}\text { strain before fracture } \\
{[\%]}\end{array}$ \\
\hline Standard Cement & 1844 & 93.77 & 33.78 \\
\hline Cement + Cefazolin & 1593 & 85.43 & 39.55 \\
\hline Cement + Cefuroxime & 1776 & 82.39 & 34.24 \\
\hline Cement + Ceftazidime & 1774 & 92.30 & 29.62 \\
\hline Cement + Meropenem & 1713 & 85.98 & 37.99 \\
\hline Cement + Vancomycin & 1782 & 84.65 & 27.83 \\
\hline Cement + Gentamicin & 1203 & 47.29 & 29.81 \\
\hline Cement + Clindamycin & 1111 & 49.55 & \\
\hline
\end{tabular}

Table 2

VALUES OF E MODULUS, YIELD STRESS AND COMPRESSION STRAIN FOR BARS BEFORE THE APPARITION OF FIRST CRACKS DURING COMPRESSION TEST 

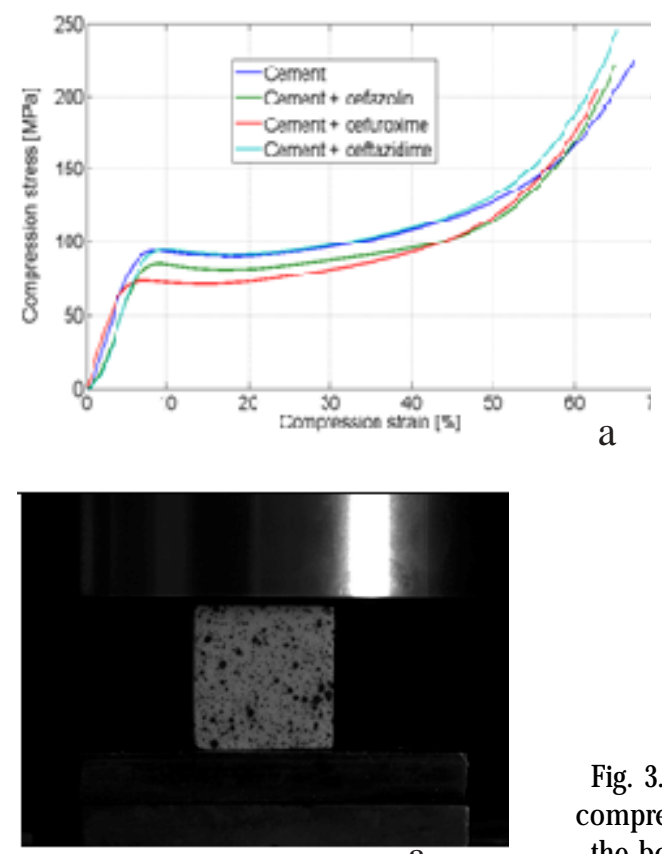

a

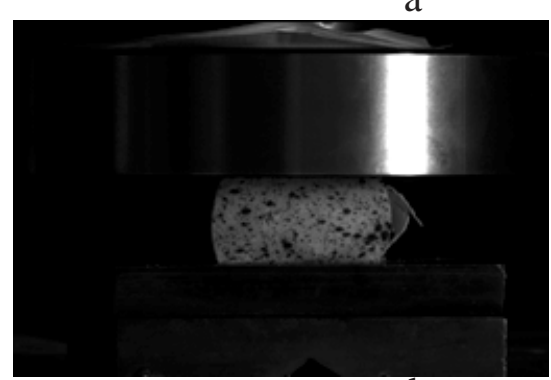

b

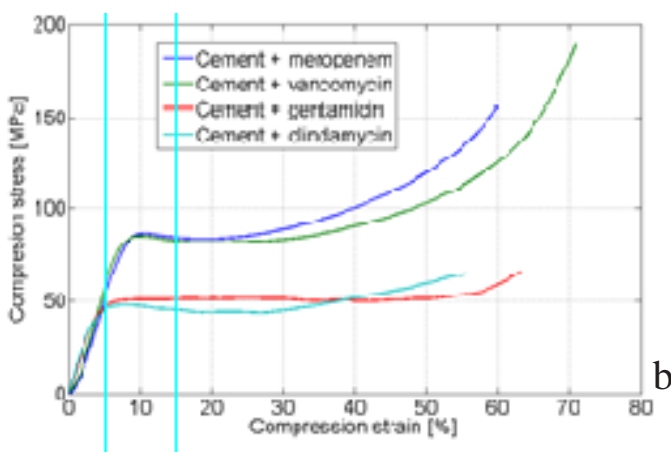

Fig. 2. Curves of the compression test for different mixtures

Fig. 3. Bar during compression test at the beginning (a) and at the end of the test (b)

In case of Standard Cement we have obtained values of $1844 \mathrm{MPa}$ for E modulus, 93.77 MPa for Yield stress respectively $33.78 \mathrm{MPa}$ to the strain before fracture.

From the results shown in table 2 and from the compression test charts show $n$ in figure 2 we can observe that the $E$ modulus value decreases with the addition of antibiotics in all 7 cases presented, so by introducing the antibiotic the orthopaedic cement gains in elasticity. This finding is sustained by the results of a study that Bohm published in 2012, aanalyzing the migration of femoral component using radiostereometric analysis (RSA), he conclude that there was clinically no significant differences

in stem subsidence or retroversion between antibiotic loaded cement and control group during a two-year followup period, suggesting that there might be no clinical significant decrease in cement properties by mixing antibiotics [15].

In the case of cement with gentamicin and clindamycin is found a significant decrease in mechanical strength, we have obtain the Yield stress values of $47.29 \mathrm{MPa}$ in the case that cement plus gentamicin and $49.55 \mathrm{MPa}$ for cement plus clindamycin. If we compared these results to the amount of Yield stress standard for cement we found decreased resistance properties with $50.43 \%$ when adding gentamicin, respectively $47.16 \%$ when adding clindamycin. Strain Before Fracture also decrease in the tw o cases: $27.83 \%$ gentamicin, respectively $29.81 \%$ clindamycin. Even if $\mathrm{E}$ modulus decreases in all cases we have observed that for the two above mentioned samples (mixed with gentamicin and clindamycin) its value decreases by $34.76 \%$ with gentamicin respectively $39.75 \%$ with clindamycin. These findings can be explained by the fact that only two of the seven analyzed antibiotics are introduced into the mixture in the liquid state. These results are consistent with the findings of Seldes. In a study published in 2005 he find also lower mechanical properties of cement containing liquid gentamicin, but due to its antibacterial properties and cost-effectiveness he recommend the usage of these combination [16].

We have also found that the addition of any of these two antibiotics in the standard cement results in a major deterioration of the mechanical strength properties. However, Yield stress values are values for these two cases are satisfactory considering the high forces used for the compression test, so the deterioration of cement mechanical properties does not appear to alter its behavior

\begin{tabular}{|l|c|c|c|}
\hline \multicolumn{1}{|c|}{ Test Bar } & $\begin{array}{c}\text { Major strain } \\
{[\%]}\end{array}$ & $\begin{array}{c}\text { Minor strain } \\
{[\%]}\end{array}$ & Von Mises strain [\%] \\
\hline Standard Cement & 37.1 & 41.2 & 69.5 \\
\hline Cement + Cefazolin & 31.0 & 41.1 & 56.7 \\
\hline Cement + Cefuroxime & 36.7 & 38.3 & 54.7 \\
\hline Cement + Ceftazidime & 34.3 & 39.6 & 60.3 \\
\hline Cement + Meropenem & 36.8 & 34.7 & 50.6 \\
\hline Cement + Vancomycin & 36.3 & 42.1 & 64.4 \\
\hline Cement + Gentamicin & 23.9 & 31.2 & 50.5 \\
\hline Cement + Clindamycin & 24.8 & 32.8 & 51.4 \\
\hline
\end{tabular}

Table 3

VALUES MAJOR STRAIN, MINOR STRAIN AND VON MISES STRAIN FOR BARS IMMEDIATELY AFTER

THE APPARITION OF FIRST CRACKS DURING COMPRESSION TEST 


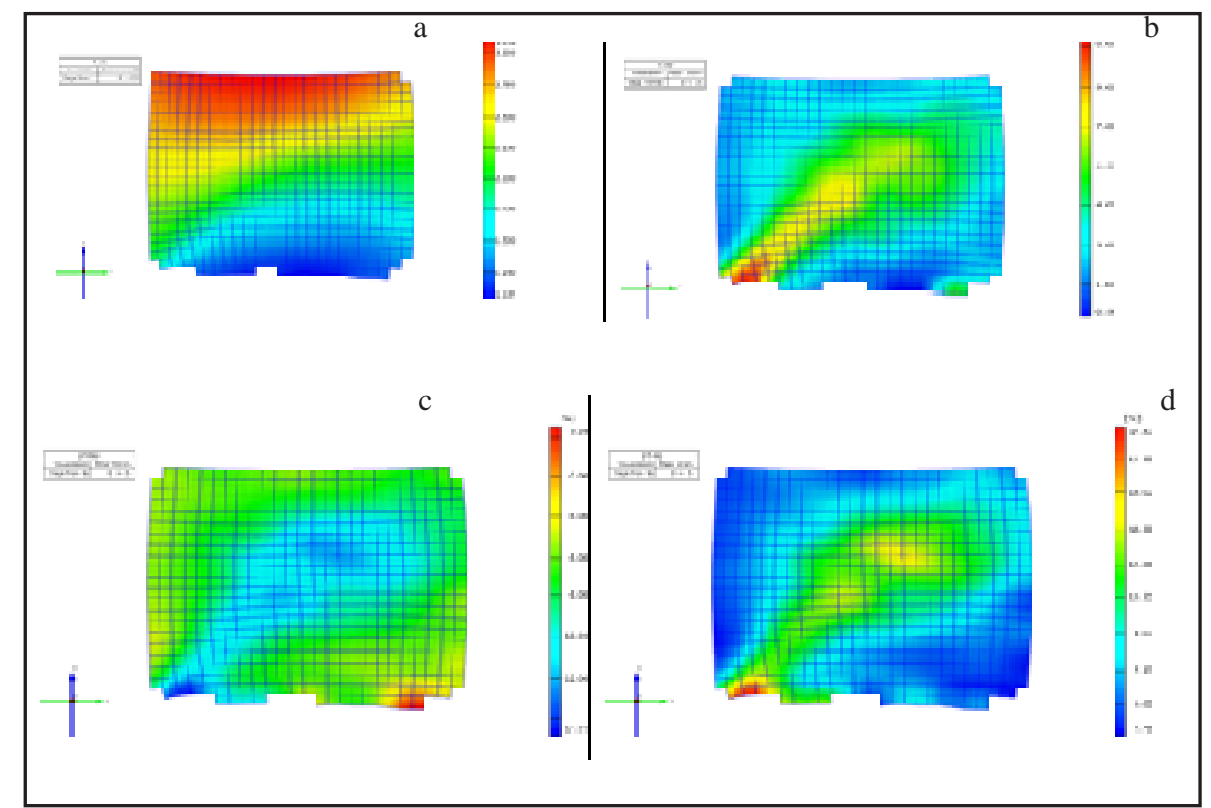

Fig. 4. Strain results at $10 \%$ compression

a) Total displacement [mm] at $10 \%$ compression

b) Major strain [\%] at 10\% compression

c) Minor strain [\%] at 10\% compression

d) Von Mises strain [\%] at 10\% compression

in normal condition inside human body, local forces being much lower than the ones used in the present test.

During the compression tests on the Instron machine, the samples were analyzed with the optical analyzer of the company Aramis Gom. Images were acquired until after the moment of the first cracks. In table 3 the results obtained are presented for Major strain, Minor strain and Von Mises strain for the eight tests (one for each antibiotic plus the standard cement) immediately after the appearance of the first cracks.

From the study data presented in table 3 we can observe that the presence of the antibiotic lead to an insignificant change of behavior in terms of major strain, minor strain and Von Mises strain with decreased values in comparison with standard cement when cefazolin, cefuroxime, ceftazidime, meropnem and vancomycin were added to the cement. A significant decreasing occurs when gentamicin and clindamycin were added, noticing values significantly reduced compared to standard cement. We can then conclude that cement mixed with the two antibiotics supports significantly lower local deformations at compression, this leading to a decrease in mechanical strength, as it has been found also in the compression test curve. Lautenschlager obtained similar results with our study, showing that adding high-dose ( $>4.5 \mathrm{~g}$ of gentamicin powder per $40 \mathrm{~g}$ cement) or the admixture of liquid antibiotics could cause a decrease in mechanical strength of antibiotic cement [17].

In figures 4, 5, and 6 are presented the optical analysis results for cement + meropenem sample at different degrees of deformation, corresponding to compression of $10 \%, 20 \%$ and immediately after appearance of the first cracks in the specimen.

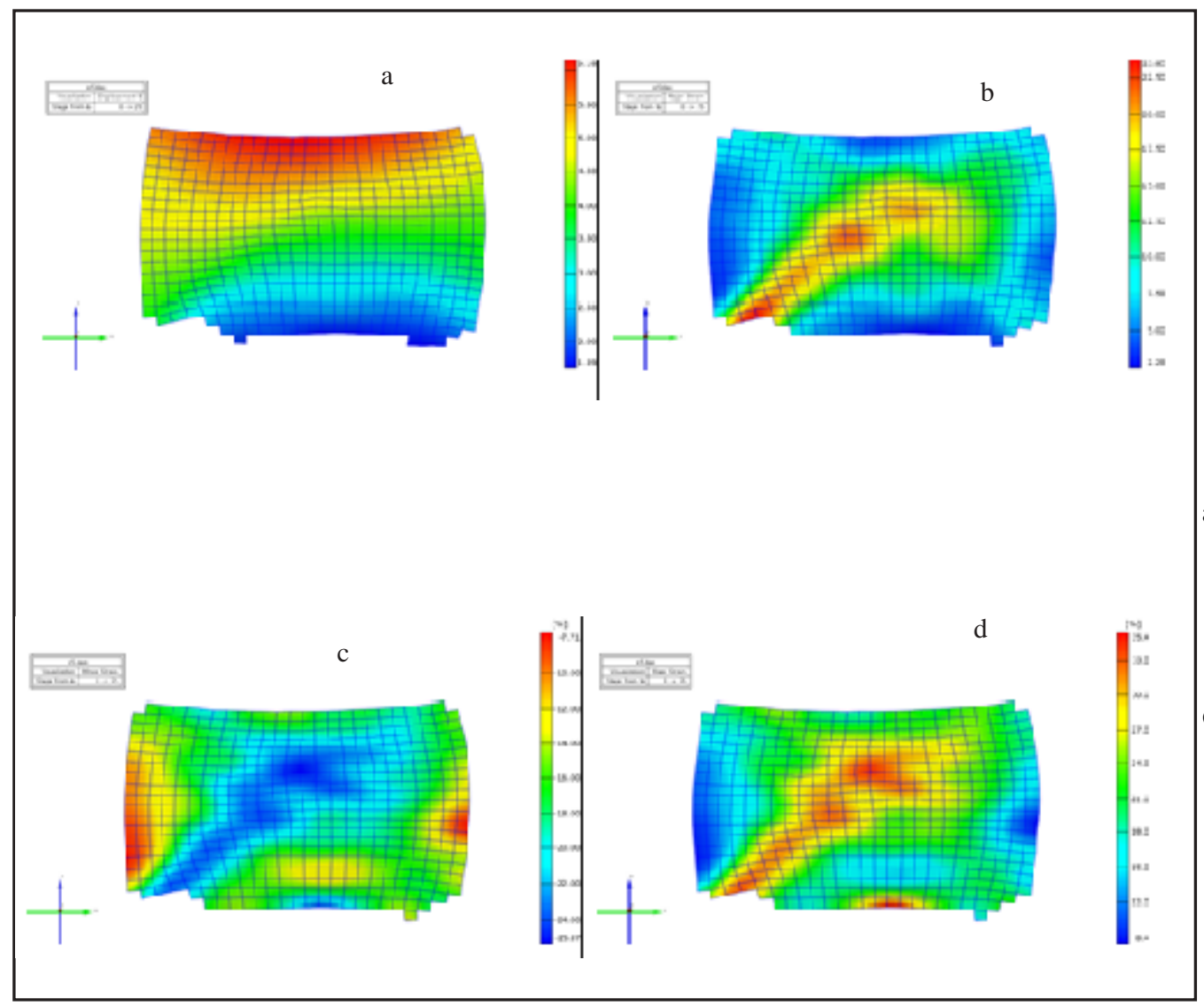

Fig. 5. Strain results at $20 \%$ compression

a) Total displacement [ $\mathrm{mm}]$ at $20 \%$ compression

b) Major strain [\%] at $20 \%$ compression

c) Minor strain [\%] at 20\% compression

d) Von Mises strain [\%] at 20\% compression 


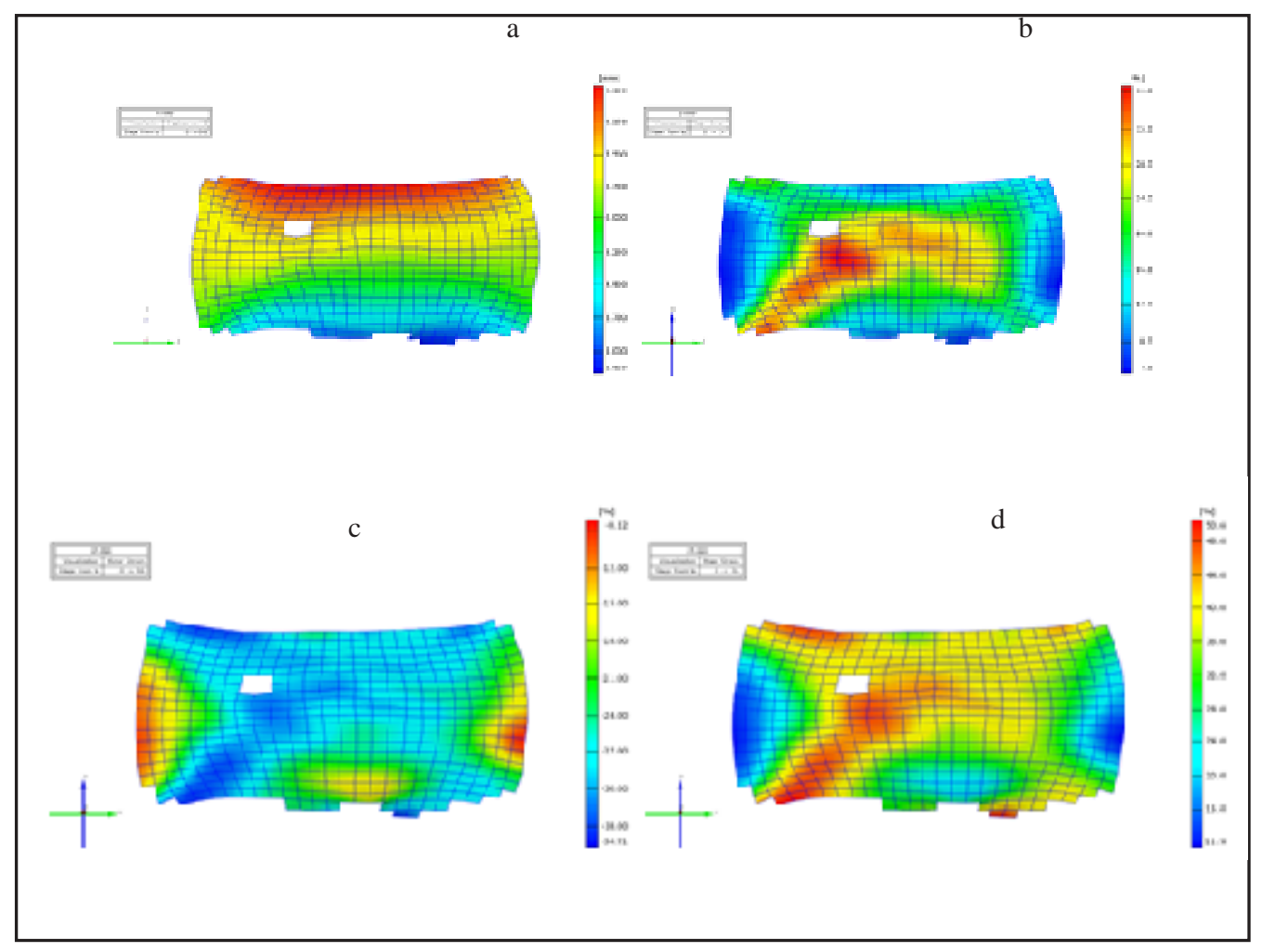

Fig. 6 Strain results after the first crack appearance

a)Total displacement [ $\mathrm{mm}$ ] after the first crack appearance

b) Major strain [\%] after the first crack appearance

c) Minor strain [\%] after the first crack appearance

d) Von Mises strain after the first crack appearance

The Aramis program allows the determination of several different types of deformations: Logarithmic Strain, Green Strain and Engineering Strain. Of these, we have chosen to present Engineering Strain. By analyzing images in the figures above itcan be seen that, as expected, major strain, minor strain and Von Mises strain values are increasing with the degree of deformation, reaching at the end of the test values of 36.8 for major strain, 34.7 for minor strain and 50.6 for Von Mises strain. These maximal values appear in the diagonal direction of the specimen at an angle of 45 degrees to the direction of compression force application since the degree of deformation is $10 \%$. With the increasing of compression local maximal deformation occurred on the other diagonal that is still 45 degrees, which is breaking shear specific. One can also notice that due to the Poisson effect specimen widening occurs, the degree of widening increasing with increasing deformation.

Bucholz already in 1984 suggest that antibiotics should not be added in liquid form, as this can lead to a $40 \%$ reduction in compressive strength in vitro, but the addition of $2 \mathrm{~g}$ of gentamicin, cloxacillin or cefazolin to a $40 \mathrm{~g} \mathrm{mix}$ of polymer has no significant effect on the short-term mechanical properties of Simplex-P (Stryker Orthopaedics) and Palacos-R (Heraeus Medical Gmbh) cements [18]. The few mechanical studies performed have assessed the static short-term mechanical properties, but these are less clinically relevant than the fatigue life or visco-elastic properties [19]. There is a need for continued research performed under standardized conditions and using modern techniques of cement preparations [20].

The limits of this study are related to the fact that we have used a reduced number of experimental bars which does not allow a statistical relevant analysis, the loading test was not performed at 37 degrees Celsius, which might be susceptible to influence the elastic properties of the cement (as in human body), and there is no fatigue testing. Nevertheless, all tests reveal same mechanical behavior of all bars.

Sanz-Ruiz, in a study published in 2013 show that antibiotic selection did not influence wear properties of the cement tested in dry conditions, however, in liquid medium, there were higher frictional coefficients and wear for vancomycin and cefazolin loaded cement. These results suggest that antibiotic cements behave differently in liquid and that the molecular characteristics of antibiotics are essential for determining this influence. Therefore, we need more studies to fully understand the mechanical properties of antibiotic loaded cement [21].

The data obtained in this study will be the starting points for analyzes using the finite element method of endoprostesis that use mixtures of cement - antibiotic (mentioned in this paper) for fixation. Finite element analysis (FEA) is used widely since the 1960's with applications in the fields of engineering and bioengineering [22].

\section{Conclusions}

Mixing antibiotics in Orthopedic cement leads to minor decrease of the mechanical properties for cefazolin, cefuroxime, ceftazidime, meropenem and vancomycin and a mechanical significant decrease for gentamicin and clindamycin.

This important alteration of mechanical properties for gentamicin and clindamycin is probably due to the fact that the two antibiotics are mixed in the liquid state in contrast to the other antibiotics which are in pow der form.

However, in the case of gentamicin and clindamycin this decrease of the mechanical properties does not lead to major problems in the mechanical behavior of the mixture, the real demands for the antibiotic cement mixture being lower that the deformation limit values.

All tested antibiotics used in this study does not change the mechanical behavior of the orthopaedic cement when mixed in therapeutic doses, all alterations seems to be at a level below clinical significance.

\section{References}

1. GRECU, D., ANTONIAC, I., TRANTE, O., NICULESCU, M., LUPESCU, 0. Failure Analysis of Retrieved Polyethylene Insert in Total Knee Replacement, Mat. Plast., 53, no. 4, 2016, p. 776

2. JAEBLON T Polymethylmethacrylate: properties and contemporary uses in orthopaedics. J Am Acad Orthop Surg (2010) 18: 297-305 
3. PARVIZI J, SALEH KJ, RAGLAND PS, POUR AE, MONT MA Efficacy of antibiotic-impregnated cement in total hip Replacement: A metaanalysis. Acta Orthop 79: 335-341(2008). doi:10.1080/ 17453670710015229

4. RANDELLI P, EVOLA F R, CABITZA P, POLLI L, DENTI M, VAIENTI L, Prophylactic use of antibiotic-loaded bone cement in primary total knee replacement Knee Surg Sports Traumatol Arthrosc (2010) 18:181186 DOI 10.1007/s00167-009-0921-y

5. BOSCO J A, BOOKMAN J, SLOVER J, EDUSEI E, LEVINE B, Principles of Antibiotic Prophylaxis in Total J oint Arthroplasty: Current Concepts, J Am Acad Orthop Surg 2015;23: e27-e35, August 2015, Vol 23, No 8, http://dx.doi.org/10.5435/JAAOS-D-15-00017

6. PARVIZI J, SALEH KJ , RAGLAND PS, POUR AE, MONT MA. Efficacy of antibiotic impregnated cement in total hip replacement. Acta Orthopaedica. 2008;79(3):335-

7. LEWIS G. Properties of antibiotic-loaded acrylic bone cements for use incemented arthroplasties: a state-of-the-art review. Journal of Biomedical Materials Research: Part B Applied Biomaterials. 2009;89(2):558-574

8. QADIR R, LOCKWOOD OCHSNER J, CHIMENTO G F, MEYER M S WADDELL B, ZAVATSKY J M, Establishing a Role for Vancomycin Powder Application for Prosthetic J oint Infection Prevention-Results of a Wear Simulation Study The J ournal of Arthroplasty, Volume 29, Issue 7 Published online: February 17, 2014, DOI: http://dx.doi.org/10.1016/ j.arth.2014.02.012

9. ABREU MFM, GOBBI RG, ZENAIDE MR, CAMPOS GC, PEREIRA CAM, PÉCORA JR, ET AL. Biomechanical evaluation of orthopaedic cement combined with antibiotic and methylene blue. Acta Ortop Bras. [online]. 2009; 17(3):162-6. Available from URL: http:// www.scielo.br/aob10. BALEANI M, PERSSON C, ZOLEZZI C, ANDOLLINA A, BORRELLI AM, TIGANI D. Biological and biomechanical effects of vancomycin and meropenem in acrylic bone cement. J ournal of Arthroplasty. 2008;23(8):1232-1238.

11. CHANG Y, TAI CL, HSIEH PH, UENG SW. Gentamicin in bone cement: A potentially more effective prophylactic measure of infection in joint arthroplasty. Bone and J oint Research. 2013 15;2(10):220-226 12. MARTÍNEZ-MORENO J, MURA C, MERINO V, NACHER A, CLIMENTE M, MERINO-SANJUÁN M, Study of the Influence of Bone Cement Type and Mixing Method on the Bioactivity and the Elution Kinetics of
Ciprofloxacin The Journal of Arthroplasty, Volume 30, Issue 7,DOI: http://dx.doi.org/10.1016/j.arth.2015.02.016

13. HSU Y H, HU C C, HSIEH PH, SHIH H N, STEVE W.N. UENG, CHANG $Y$, Vancomycin and Ceftazidime in Bone Cement as a Potentially Effective Treatment for Knee Periprosthetic Joint Infection J Bone J ointSurg Am. 2017;99:223-31 d http://dx.doi.org/10.2106/J BJ S.16.00290 14. POSTAK P D, GREENWALD A S, The Influence Of Antibiotics On The Fatigue Life Of Acrylic Bone Cement, The Journal Of Bone \& J oint Surgery · J bjs.Org Volume 88-A · Supplement $4 \cdot$ 148-155, 2006 15. BOHM E, PETRAK M, GASCOYNE T, TURGEON T The effect of adding tobramycin to Simplex $P$ cement on femoral stem micromotion as measured by radiostereometric analysis: a 2-year randomized controlled trial. Acta Orthop 83: (2012) 115-120. doi:10.3109/ 17453674.2011.652885

16. SELDES RM, WINIARSKY R, JORDAN LC, BALDINI T, BRAUSE B et al. Liquid gentamicin in bone cement: a laboratory study of a potentially more costeffective cement spacer. J Bone Joint Surg (Am) 87: 2682672. (2005) doi:10.2106/J BJS.C.00728.

17. LAUTENSCHLAGER EP, JACOBS J], MARSHALL GW, MEYER PR JR Mechanical properties of bone cements containing large doses of antibiotic powders.J Biomed Mater Res 10: 929-938. (1976) doi:10.1002/ jbm. 820100610

18. BUCHHOLZ HW, ELSON RA, HEINERT K. Antibiotic-loaded acrylic cement: current concepts. Clin Orthop Relat Res. 1984;190:96-108

19. LEE AJ, LING RS, GHEDUZZI S, SIMON JP, RENFRO RJ. Factors affecting the mechanical and viscoelastic properties of acrylic bone cement. J Mater Sci Mater Med 2002;13:723-33.

20. LIU C, GREEN SM, WATKINS ND, GREGG PJ, MCCASKIE AQ. Creep behaviour comparison of CMW 1 and palacos R-40 clinical bone cements.J Mater Sci Mater Med2002;13:1021-8.

21. SANZ-RUIZ P, PAZ E, ABENOJAR J, JUAN CARLOS DEL REAL, VAQUERO J, FORRIOL F, Effects of Vancomycin, Cefazolin and Test Conditions on the Wear Behavior of Bone Cement The J ournal of Arthroplasty, Volume 29, Issue Published online: May 22, 2013,DOI: http://dx.doi.org/10.1016/j.arth.2013.04.008.

22. COMAN, C., GHERGIC, D.L, PATROI, D.N., TARCOLEA, M, COMANEANU, R.M., BARBU, H.M., Comparative Assessment of Resistance Against Experimental Forces of Mixed Prosthetic Restorations, Mat. Plast., 53, 1, 2016, p. 91

Manuscript received: 17.12 .2016 


\title{
REVISTA DE CHIMIE SI
}

\section{REVISTA MATERIALE PLASTICE} POT FI ACCESATE GRATUIT LA URMATOARELE ADRESE:

http://www.revistadechimie.ro/ http://www.revmaterialeplastice.ro/

\section{FREE WEB ACCESS FOR REVISTA DE CHIMIE AND MATERIALE PLASTICE}

\author{
http://www.revistadechimie.ro/ \\ http://www.revmaterialeplastice.ro/
}

